\title{
Patients with Left Ventricular (LV) Dysfunction: Is OPCAB Advantageous over Conventional CABG in our settings?
}

\author{
M Kamruzzaman ${ }^{1}$, N Hosain ${ }^{2}$, MK Hassan ${ }^{3}$, SKA Razzak ${ }^{4}$, NU Ahmed ${ }^{3}$ \\ ${ }^{1}$ Department of Cardiovascular \& Thoracic Surgery, Combined Military Hospital, Dhaka. ${ }^{2}$ Dept. of \\ Cardiovascular Surgery, Chittagong Medical College, Chittagong. ${ }^{3}$ Dept. of Cardiovascular Surgery, \\ National Institute of Cardiovascular Diseases, Dhaka, ${ }^{4}$ Dept. of Pediatric Cardiology, National \\ Institute of Cardiovascular Diseases, Dhaka
}

Keywords:

Left ventricular function, $C A B G$, $O P C A B$.

\begin{abstract}
:
Objective: Off-pump CABG (OPCAB) is a well established surgical procedure in Bangladesh now. Majority of Bangladeshi patients having CABG are undergoing OPCAB procedures these days. Patients with left ventricular dysfunction are known to be particularly at risk of complications after surgical coronary revascularization. Off-pump procedure can be considered in these patients, avoiding the potentially damaging effect of cardiopulmonary bypass (CPB). Patients with left ventricular dysfunction are thus thought to be ideal OPCAB candidates. This study is undertaken to check the advantage of OPCAB over conventional CABG of Bangladeshi patients with left ventricular dysfunction.
\end{abstract}

Methods: This is a prospective clinical trial done in National Institute of Cardiovascular Diseases (NICVD), Dhaka during the period of January 2006 to Dec 2007. Among the 52 patients 26 patients underwent $O P C A B$ with preoperative ejection fraction $(E F) 35.2 \pm 3.2 \%$ and rest 26 patients had conventional bypass (CCABG) with preoperative EF $33.4 \pm 3.8 \%$. Different variables were evaluated and compared. Echocardiography was used both pre and postoperatively to assess the LVEF, LVIDd and LVIDs and regional wall motion abnormality and to assess the presence or absence of ischemia or infarction. Data were collected by interview schedule and checklist. Data were analyzed by standard statistical methods.

Results: In this small series of patients with left ventricular dysfunction, off-pump CABG was carried out with good early outcome; with low mortality and morbidity and significant improvement in postoperative left ventricular function. There was no significant difference between the groups in terms of change in EF, LVIDd and LVIDs.

Conclusion: From this study it can be concluded that both the surgical strategies improved the myocardial function and early outcome in patients with left ventricular dysfunction. However $O P C A B$ surgery has a somewhat better result regarding ventilation time and ICU stay. Thus both $O P C A B$ and on pump surgery can be performed safely and effectively in patients with left ventricular dysfunction with good results and low mortality.

(Cardiovasc.j. 2011; 3(2): 131-135)

\section{Introduction:}

Surgical revascularization for ischemic heart disease has been an innovation of the past decades and now off-pump coronary artery bypass grafting (OPCAB) is widely accepted and considered to be a safe method for myocardial revascularization. In addition $\mathrm{OPCAB}$ is considered to be safe for high risk patients. ${ }^{1}$ Cardiopulmonary Bypass (CPB) has facilitated surgery on coronary arteries and as a result millions of patients with coronary artery disease have led healthier and longer lives. The development of cardiac stabilizers in the late 1990s allowed wide spread applications of alternative techniques of coronary revascularization, which do not require CPB. Satisfactory coronary revascularization without attendant morbidity of CPB holds obvious appeal, and off-pump CABG has become popular. Many studies reported reduced operative morbidity with $\mathrm{OPCAB}$ relative to $\mathrm{CABG}$ on $\mathrm{CPB} .^{2} \mathrm{OPCAB}$ is feasible and applicable for patients with depressed left ventricular (LV) function. This high-risk group can potentially benefit from the off-pump approach. ${ }^{3}$

Address of Correspondence: Md. Kamruzzaman, Department of Cardiovascular \& Thoracic Surgery, Combined Military Hospital, Dhaka, Bangladesh. 
There is an increasing incidence of moderate to severe left ventricular dysfunction in patients referred for CABG due to widespread use of thrombolysis, increased surgery in patients with recent acute myocardial infarction and angioplasty, which delays surgical intervention until coronary arteriosclerosis is more extensive and left ventricular dysfunction more severe, placing patients at much higher surgical risk ${ }^{4}$. Left ventricular function is customarily reported as ejection fraction (EF), measured either by echocardiography, cineangiography or by radionuclide scanning. An ejection fraction between 60 and $75 \%$ is considered normal. A mild to moderate depression of ventricular function is represented by an ejection fraction of 40 to $60 \%$. Those below $40 \%$ represent moderate depression and those below $30 \%$ severe depression. ${ }^{5}$ Symptoms of congestive heart failure appear with increasing frequency with an ejection fraction below $30 \%$ and are common with an ejection fraction below 20\%. Effective bypass surgery that relieves all major obstructions is usually associated with an increase in ejection fraction of at least $10 \%$ if viable myocardium is significant, apparently because blood flow is restored to viable but nonfunctioning ischemic muscle. ${ }^{5}$

\section{Methods:}

The study was conducted in the department of cardiovascular surgery, National Institute of Cardiovascular Diseases, (NICVD) Dhaka, Bangladesh between January 2006 and Dec 2007. Patients of ischemic heart disease (IHD) with left ventricular dysfunction (LVEF d"40\% calculated by echocardiography undergoing CABG) admitted in NICVD for coronary artery bypass grafting were selected for this study. Patients with left ventricular aneurysm, co-existing valvular or congenital heart disease and those aged over 70 were excluded from the study. Patients with recent MI (within 6 weeks), redo CABGs and emergency CABG patients were also excluded.

Diagnosis was confirmed by history, clinical examination, ECG, echocardiography, coronary angiography and other required laboratory investigations. The cases were selected by specific inclusion and exclusion criteria. The treatment strategy was planned preoperatively after assessment of various parameters and the patients were divided into two groups i.e. Group A and Group B subjected to OPCAB and on-pump CABG respectively. Preoperative, peroperative, and postoperative variables were recorded in a preformed data sheet. Follow-up of the patients were done after one month and six months postoperatively. Relevant findings were recorded in the data sheet. The collected data were compiled, analyzed and presented by using standard statistical methods.

The participants were explained the purpose and the importance of the study. The study was conducted with signed informed consent from all the participants. Interview schedule, hospital records and investigations using pre-formed data form collected data.

Patients under study had undergone Echocardiographic examination Preoperatively and 6 months postoperatively. Assessment of left ventricular function was done by echocardiography. Ejection fraction (EF\%) was determined by 'cubed equation' method using two dimensional (2D) and M-mode echocardiography, which were performed preoperatively, and 6 months after operation to evaluate left ventricular ejection fraction (LVEF\%), chamber dimension, LVIDd and LVIDs.

\section{Results:}

Of the 52 patients selected for coronary artery bypass graft (CABG), 26 were assigned to off-pump group (Group-A) and 26 to on-pump group (GroupB). The purpose of the study was to evaluate the early outcome of OPCAB in patients with left ventricular dysfunction and to compare the results with that of on-pump group. The findings of the study obtained from data analysis are presented below.

\section{Age \& sex distribution:}

$65.4 \%$ of the patients in the off-pump group were over 55 years of age, while $69.2 \%$ of the on-pump group was over 55 years of age. The difference between the two groups in terms of age was not statistically significant $(55.5 \pm 4.5$ years vs. $57.7 \pm$ 5.4 years, $p$ value 0.123 ). A preponderance of male sex was observed in both off-pump (88.5\%) and onpump group (84.6\%). The male to female ratio of the selected patients was roughly 8:1. 
Baseline CCS functional status and NYHA functional class:

CCS functional class at baseline shows that majority of off-pump and on-pump groups (80.76\% in offpump and $76.92 \%$ in on-pump) had class-III anginal pain. Very few cases of both the groups had classII and class-IV disease. NYHA functional class demonstrates that over three-quarter $(76.9 \%)$ of the patients in both off-pump and on-pump group had NYHA class-III.

Ventricular function by echocardiography:

Table I shows the ventricular function determined by echocardiography at baseline. The mean LVEF, LVIDd and LVIDs all were found to be homogeneously distributed between groups (35.2 \pm 3.2 vs. $33.4 \pm 3.8, p$ value $0.069 ; 53.7 \pm 1.8$ vs. $54.1 \pm 2.3, p$ value 0.465 and $43.2 \pm 2.0$ vs. $43.5 \pm$ $1.5, p$ value 0.544 respectively).

Table-I

Baseline ventricular function between groups $(n=52)$

\begin{tabular}{lccc}
\hline $\begin{array}{l}\text { Ventricular function } \\
\text { at baseline }\end{array}$ & \multicolumn{2}{c}{ Group } & -value $^{\#}$ \\
& $\begin{array}{c}\text { Off-pump } \\
\text { (n = 26) }\end{array}$ & $\begin{array}{c}\text { On-pump } \\
\text { (n = 26) }\end{array}$ & \\
\hline LVEF (\%) & $35.2 \pm 3.2$ & $33.4 \pm 3.8$ & 0.069 \\
LVIDd (in mm) & $53.7 \pm 1.8$ & $54.1 \pm 2.3$ & 0.465 \\
LVIDs (in mm) & $43.2 \pm 2.0$ & $43.5 \pm 1.5$ & 0.544 \\
\hline
\end{tabular}

Values are expressed as mean $\pm \mathrm{SD}$, *statistcal analysis was done by Student's 't' test.

Table II compares the ventricular function between groups 6 months after CABG. Both the groups improved EF from their baseline status. However, difference in improvement between the groups was not marked ( $p$ value 0.098 ). The groups were also not observed to be significantly different in terms of mean LVIDd and LVIDs.

\section{Table-II}

Ventricular function 6 month after $C A B G(n=43)$

\begin{tabular}{lccc}
\hline Variables & \multicolumn{2}{c}{ Group } & p-value* \\
\cline { 2 - 3 } & $\begin{array}{c}\text { Off-pump } \\
(\mathrm{n}=23)\end{array}$ & $\begin{array}{c}\text { On-pump } \\
\text { (n = 20) }\end{array}$ & \\
\hline Echo EF (\%) & $48.5 \pm 2.9$ & $46.2 \pm 5.2$ & 0.098 \\
LVIDd (in mm) & $50.4 \pm 2.9$ & $51.7 \pm 1.3$ & 0.085 \\
LVIDs (in mm) & $40.8 \pm 1.4$ & $41.6 \pm 2.4$ & 0.174 \\
\hline
\end{tabular}

Values are expressed as mean $\pm \mathrm{SD}$, *statistcal analysis was done by Student's 't' test.
Table III compares the changes in echo parameters in the off-pump group between baseline and 6 months after CABG. The mean echo EF significantly improved from its baseline status. The LVIDd and LVIDs significantly reduced 6 months after CABG from their baseline figures.

\section{Table-III}

Changes in echo parameters in off-pump group after 6 months

\begin{tabular}{lccc}
\hline $\begin{array}{l}\text { Echo } \\
\text { parameters }\end{array}$ & $\begin{array}{c}\text { At baseline } \\
(\mathrm{n}=23)\end{array}$ & $\begin{array}{c}\text { After } \\
6 \text { months } \\
(\mathrm{n}=23)\end{array}$ & p-value* \\
\hline Echo EF (\%) & $34.9 \pm 3.1$ & $48.5 \pm 3.0$ & $<0.001$ \\
LVIDd (in mm) & $54.2 \pm 2.0$ & $50.4 \pm 2.9$ & $<0.001$ \\
LVIDs (in mm) & $44.1 \pm 2.2$ & $40.8 \pm 1.4$ & $<0.001$ \\
\hline
\end{tabular}

Values are expressed as mean $\pm \mathrm{SD}$, *statistcal analysis was done by Student's ' $t$ ' test.

Table-IV compares the Echo parameters in the onpump group between baseline and 6 months after CABG. The mean echo EF increased, whereas the mean LVIDd and LVIDs significantly decreased.

Table-IV

Changes in echo parameters in on-pump group after 6 months

\begin{tabular}{lccc}
\hline Echo parameters & \multicolumn{2}{c}{ On-pump } & p-value \\
\cline { 2 - 3 } & $\begin{array}{c}\text { At baseline } \\
(\mathrm{n}=20)\end{array}$ & $\begin{array}{c}\text { After } 6 \\
\text { months } \\
(\mathrm{n}=20)\end{array}$ & \\
\hline Echo EF (\%) & $34.2 \pm 3.7$ & $46.2 \pm 5.2$ & $<0.001$ \\
LVIDd (in mm) & $56.4 \pm 2.1$ & $52.3 \pm 1.8$ & $<0.001$ \\
LVIDs (in mm) & $44.8 \pm 1.9$ & $42.6 \pm 2.4$ & $<0.001$ \\
\hline
\end{tabular}

Values are expressed as mean $\pm \mathrm{SD}$, *statistcal analysis was done by Student's 't' test.

In terms of changes in LVEF following CABG, offpump group apparently experienced a better improvement compared to on-pump group. However, the difference between the groups in terms of improvement of ejection fraction (EF) was not statistically significant (Table V).

\section{Table V}

Comparison of improvement in $E F$ between groups

\begin{tabular}{lcc}
\hline Group & $\begin{array}{c}\text { Improvement } \\
\text { of EF (\%) }\end{array}$ & p-value $^{*}$ \\
\hline Off-pump $(\mathrm{n}=23)$ & $13.6 \pm 1.7$ & 0.097 \\
On-pump (n=20) & $12.6 \pm 2.3$ & \\
\hline
\end{tabular}

Values are expressed as mean $\pm \mathrm{SD}$, *statistcal analysis was done by Student's 't' test. 


\section{Discussion:}

National Institute of Cardiovascular Diseases (NICVD), Dhaka Bangladesh, has been performing the central role in the field of cardiac surgery countrywide. From January 2006 to December 2007 a total 432 CABG surgery were performed of which 262 were performed off-pump and rest 170 were performed on-pump (CCAB) i.e. under Cardio pulmonary bypass. This study was conducted in the department of Cardiovascular Surgery at NICVD during the period of January 2006 to December 2007 with the purpose of comparing the early outcome of off-pump coronary artery bypass grafting (OPCAB) with those on pump in patients with left ventricular dysfunction. A total of 52 patients were selected; of them 26 underwent OPCAB surgery while the other 26 had CCABG surgery.

In our study there was no bias in terms of age distribution and both sexes were homogenously distributed in OPCAB and on-pump group. In our present study the predominant risk factors were smoking and hypertension. (50.0\% vs $46.2 \%$ and $59.2 \%$ vs $61.5 \%$ ) in off-pump vs on-pump group respectively. All the common risk factors like smoking, hypertension, diabetes and dyslipidemia were homogenously distributed between the groups. There was no significant difference between the groups in terms of distal anastomoses. The total operation time in OPCAB group (227.50 $\pm 15.7 \mathrm{~min}$ ) was significantly less than that of on-pump group (291.42 $\pm 58.1 \mathrm{~min})$ in this study. In our study operative mortality was $7.7 \%$ in onpump group where as there was no mortality in OPCAB group, however it was not statistically significant. The mean duration of ventilation in the off-pump group was significantly less (16.1 \pm 1.8 hours) than that required in on-pump group $(25.7 \pm 9.7$ hours $)(\mathrm{p}<0.001)$. The mean ICU stay was also much less in the off-pump group (31.7 \pm 3.6 hours) than that needed in the on-pump group $(45.5 \pm 7.4$ hours $)(p<0.001)$.

Our study revealed that $76.92 \%$ patients in OPCAB group and $80.76 \%$ in on-pump group were symptomatic with anginal pain having CCS functional class III preoperatively. Thus in terms of CCS class there were no significant difference preoperatively between the groups. Postoperatively one month after CABG in OPCAB group $43.47 \%$ and $56.52 \%$ belonged to CCS class I and II, while in on-pump group $38.1 \%$ and $57.14 \%$ were in CCS class I and II respectively with least $4.76 \%$ in class III. None of the patients in OPCAB group was found in class III. Postoperatively 6 months after CABG more than $95 \%$ of the off-pump group and $90 \%$ of the on-pump group had CCS class I and rest of the patients had CCS class II. Both the group experienced significant postoperative improvement in terms of CCS functional class after CABG but when it was compared between the groups was found to be insignificant.

Our study showed over three quarters (76.9\%) of the patients in both off-pump and on-pump group were in NYHA class III preoperatively. Though on-pump group had NYHA class IV a bit higher (11.8\%), the difference between the two groups was insignificant. Follow up data after 6 months of surgery showed more than $95.7 \%$ of the off-pump group returned to NYHA class I, compared to $85 \%$ of the on-pump group. Both the groups experienced significant improvement in NYHA functional class but when outcome was compared between the groups improvement was considered better in the off-pump group.

Youn et al. ${ }^{4}$ in a study demonstrated significant increase in LVEF on follow up echocardiography from its preoperative value in both CPB CABG \& OPCAB groups but there was no significant difference between the two groups in the degree of increase of LVEF. In OPCAB group preoperative LVEF $27.6 \%$ improved to $37.6 \%$ post operatively and in CPB CABG group LVEF improved from $27 \%$ to $34.9 \%$. This study also showed that the left ventricular end diastolic dimension and left ventricular end systolic dimension decreased significantly during follow up in both the groups but there were no significant differences between the two groups in the degree of changes of parameters.

Skorpil et al. ${ }^{6}$ reported in a study that LVEF (assessed by echocardiography) improved from $23.1 \%$ preoperatively to $36.0 \%$ post operatively. Nurözler et $\mathrm{al}^{7}$ in a study on off-pump coronary artery bypass for advanced left ventricular dysfunction showed significant improvement in LVEF in post operative course.

In our study comparison of changes in echo parameters between baseline status and 6 months 
after $\mathrm{CABG}$ in both the OPCAB and $\mathrm{CPB}$ group revealed significant improvement of $\mathrm{EF}$ from its baseline status. In off-pump group LVEF improved from its preoperative status $34.9 \pm 3.1 \%$ to $48.5 \pm 3.0 \%$ after 6 month. Similarly it was observed that in the on-pump group preoperative LVEF increased from $34.2 \pm 3.7 \%$ to $46.2 \pm 4.6 \% 6$ months after CABG. The mean difference of LVEF from baseline status to 6 month postoperatively was $13.6 \pm 1.7 \%$ in offpump group and $12.6 \pm 2.3 \%$ in on-pump group. The off-pump group experienced better improvement in LVEF compared to on-pump group, but the difference of improvement in EF between the groups was not statistically significant.

The LVIDd and LVIDs in preoperative period were homogenously distributed between the two groups (53.7 \pm 1.8 vs $54.1 \pm 2.3$ and $43.2 \pm 2.0$ vs $43.5 \pm 1.5$ ). Postoperatively 6 months after CABG LVIDd \& LVIDs was significantly reduced in both the groups from their baseline status. In OPCAB group LVIDd reduced significantly from $53.7 \pm 1.8$ to $50.4 \pm 2.9 \mathrm{~mm}$ and LVIDs reduced from $43.2 \pm 2.0$ to $40.8 \pm 1.4 \mathrm{~mm}$. In on-pump group LVIDd \& LVIDs decreased significantly from $54.1 \pm 2.3$ to $51.7 \pm 1.3 \mathrm{~mm}$ and $43.5 \pm 1.5$ to $41.6 \pm 2.4 \mathrm{~mm}$. The improvement in ventricular wall motion was much better between pre and postoperative period in both the groups. These findings indicate functional improvement as well as effectiveness of revascularization of the ischemic zone due to coronary artery bypass grafting.

\section{Conclusion:}

From this study it can be concluded that both the surgical strategies improved the myocardial function and early outcome in patients with left ventricular dysfunction. Marked improvement was observed in CCS class, NYHA class and regional wall motion abnormality 6 months postoperatively. LVEF significantly improved 6 months postoperatively in both OPCAB and on-pump groups. But the difference of improvement between the groups was not significant.

OPCAB patients however had significantly shorter ventilation time and ICU stay compared with CPB group. This gives an economic advantage both for the patient and the health care provider. The limitation of this study is definitely the small number of patients. With such small number of patients, clinical advantage of one of the methods couldn't be made. In a follow up study with enrolment of bigger number of patient could draw more conclusive decision.

\section{References:}

1. Takai H, Kobayashi J, Tagusari O, Bando K, Niwaya K, Nakajima H, Yagihara T. Off-pump coronary artery bypass grafting for acute myocardial infarction. Circulation 2006; 70: 1303-1306.

2. Williams ML, Muhlbaier LH, Schroder JN, Hata JA, Peterson ED, Smith PK, Landolfo KP, Messier RH, Davis RD, Milano CA. Risk-adjusted short-and long term outcomes for on-pump versus off-pump coronary artery bypass surgery. Circulation 2005; 112: 366-370.

3. Sharoni E, Song HK, Peterson RJ, Guyton RA, Puskas JD. Off-pump coronary artery bypass surgery for significant left ventricular dysfunction: safety, feasibility, and trends in methodology over time an early experience. Heart 2006; 92:499-502.

4. Youn YN, Chang BC, Hong YS, Kwak YL, Yoo KJ. Early and mid-term impacts of cardiopulmonary bypass on coronary artery bypass grafting in patients with poor left ventricular dysfunction: A propensity score analysis. Circulation 2007; 71: 1387-1394.

5. Spencer FC, Galloway AC, Calvin SB. Surgical management of coronary artery disease. In: Sabiston DC, Spencer FC (eds). Surgery of the chest, vol-II, $6^{\text {th }}$ edn. Philadelphia, USA: W.B.Saunders company, 1996: 1884-1909.

6. Skorpil J, Brat R, Docekal B, Motyka O. Myocardial revascularization in patients with servere left ventricular dysfunction, early and midterm results. Biomed. Papers 2004; 148(1): 55-58.

7. Nurözler F, Kutlu ST, Kücük G. Off-pump coronary bypass for advanced left ventricular dysfunction. Cardiovasc J South Afr 2007; 18: 26-29. 